Entre Ciencia e Ingeniería, vol.14, no. 27, Editorial, páginas 7-8.

DOI: https://doi.org/10.31908/19098367.1717

ISSN 1909-8367 (Impreso), ISSN 2539-4169 (En línea)

\title{
Editorial
}

\section{Los nuevos programas de ingenierías que demanda la Industria 4.0}

\section{The new engineering programs demanded by Industry 4.0}

\author{
Luis Eduardo Peláez Valencia $\mathrm{PhD}(\mathrm{c})$
}

Se ha cuestionado si determinadas carreras que llevan en su denominación la palabra ingeniería son efectivamente ingenierías. Esto, por el nivel de conexión e interacción con las ciencias exactas y ciencias aplicadas en sus justas proporciones, a propósito del título de esta revista.

Este cuestionamiento se ha favorecido, posiblemente, dado que el común de las personas hacen una distinción clara entre los ingenieros y los científicos, precisamente por la profunda ligazón que se sigue percibiendo entre la ciencia, la ingeniería y la tecnología [1].

Si se logran diferenciar los campos específicos de conocimiento y de estudio, seguramente cada programa académico logrará tener una denominación correspondiente. No es lo mismo estudiante administración para ingenieros que ingeniería administrativa; ni finanzas para ingenieros que ingeniería financiera. Es precisamente le nivel de ciencia y ciencia aplicada que cada estudio requiere lo que le ayuda a delimitar el campo de estudio y en consecuencia su denominación. La diferencia no es de valor agregado a los futuros egresados [2] sino de estructura del desarrollo del conocimiento y de la propuesta curricular.

Cada tendencia ha traído sus propias necesidades de formación. Cada forma que se la encontrado de aplicar la ciencia y la tecnología, ha llegado también con sus propias ingenierías. Este es el caso también del concepto de Industria 4.0 como tendencia, concebida en Alemania para hacer referencia a la nueva transformación digital de la industria, conocida también como "Fábrica inteligente" o "Internet industrial" [3]-[5].

En este sentido, se plantea la necesidad de apropiar la formación de recurso humano hacia los entornos, planes y necesidades propios de esta Industria [6] de tal forma que se requiere, no solo contenidos curriculares, sino propuestas que permitan hacer todo un despliegue de la ciencia y la tecnología para su desarrollo; es decir, propuestas de Ingeniería. El estudio de la OECD [7] propuso la necesidad de formular nuevos programas de Ciencia e Ingeniería para que los futuros profesionales puedan ocupar los nuevos espacios laborales y de emprendimiento en el contexto de las oportunidades emergentes que la cuarta revolución requerirá [8].

Así las cosas, se demandará la Ingeniería Matemática, Ingeniería Física, Ingeniería de las Artes Digitales, Ingeniería de la Animación, Ingeniería de la Ciencia de Datos, Ingeniería del Internet de las Cosas, Ingeniería 3D; y en fin, un sinnúmero de profesiones que obedezcan a las tendencias tecnológicas que trae la industria, pero tratadas con un estilo particular: al estilo de la ciencia aplicada, para precisamente darle un tratamiento especial al conocimiento y que su aplicación en la industria se conserve por el tiempo necesario hasta la siguiente tendencia. 
[1] A. V. Giraldo, "La relación entre la ingeniería y la ciencia," Rev. Fac. Ing. Univ. Antioquia, vol. unknown, no. 31, pp. 156-174, 2004.

[2] J. D. Simón, "Yo estudio para ser ingeniero: ¿para qué cursar administración y contabilidad?," Propósitos y Represent., vol. 6, no. 2, pp. 453-540, 2018.

[3] D. V. José Luis, "INDUSTRIA 4.0- La Transformación digital de la Industria," Rev. Ing. Deusto, vol. 16, no. 2171-858X, pp. 48-49, 2016.

[4] P. Berce, "The fourth industrial revolution," Acad. J. Manuf. Eng., vol. 14, no. 1, p. 5, 2016, doi: 10.4337/9781786430328.00006.

[5] Ministerio de las Tecnologías de la Información y las Telecomunicaciones - MINTIC, "Aspectos Básicos de la Industria 4.0,” p. 8, 2019.

[6] J. Carvajal, "La cuarta revolución industrial o industria 4.0 y su impacto en la educación superior en ingeniería en Latinoamérica y el Caribe," 15 th LACCEI Int. Multi-Conference Eng. Educ. Technol., no. July, pp. 1-5, 2017.

[7] OECD, "The Next Production Revolution," Next Prod. Revolut., p. 442, 2017, doi: 10.1787/f69a68e9-en.

[8] D. Gibson, N. Ostashewski, K. Flintoff, S. Grant, and E. Knight, "Digital badges in education," Educ. Inf. Technol., vol. 20, no. 2, pp. 403-410, 2015, doi: 10.1007/s10639-013-9291-7. 